\title{
Princípios gerais de conservação têxtil
}

Fausto Viana*

Luz García Neira**

\section{Resumo}

O objetivo maior deste artigo é analisar a conservação dos têxteis, nas suas diversas categorias, e oferecer subsídios para a maior compreensão dos materiais e estruturas que os compõem, auxiliando a sua salvaguarda, conservação e também a sua catalogação. Com isso, pretende-se aprofundar o estudo dos têxteis para fins de pesquisas históricas no Brasil, chamando a atenção de pesquisadores em diversos níveis para a importância documental deste tipo de material. O leitor que não é conservador encontrará instrumentos para que ele mesmo possa, na ausência de um profissional habilitado, contribuir para a preservação dos têxteis.

Palavras-chave: Conservação de têxteis. Preservação de patrimônio cultural.

\section{General principles of conservation for textiles}

\begin{abstract}
The main objective of this article is to discuss the conservation of textiles, in their different categories and offer support for the understanding of materials and structures that are part of them, thus helping in the storage, conservation and cataloguing. It is intended to deepen the study of textiles in historic research in Brazil, driving the attention of researchers in different levels for the documental importance of this kind of material. The reader that is not a conservator may find suitable support so that he may, whenever a capable professional is not available, help in the preservation of textiles.
\end{abstract}

Key-words: Conservation of textiles. Cultural heritage preservation. 


\section{Introdução}

A preocupação com a conservação dos têxteis é recente e bastante ligada à história da museologia. Sempre houve impulsos colecionistas, mas foi apenas no século 19 que surgiram os museus enciclopédicos. A ideia era guardar tudo que fosse possível, na tentativa de reproduzir a história da humanidade através de objetos. Com suas reservas técnicas já quase saturadas, o século 20 trouxe questionamentos acerca da existência e do material que deveria ser preservado nos museus.

O fim da Segunda Guerra Mundial marca uma nova fase no pensamento museológico. Estudos mais específicos sobre têxteis começam a surgir, sendo que apenas na década de 1960 vão-se formalizar cursos que ensinem a conservação deste tipo de acervo.

Um longo caminho foi percorrido até que se chegasse às atuais políticas curatoriais que trabalham com o fato museal: a relação do homem com o objeto é que estabelece a sua permanência ou não no museu ou na coleção. Com os têxteis não poderia ser diferente.

Têxteis não incluem apenas vestimentas, mas também tapeçarias, alfaias, coberturas de estofados, bordados e uma incrível variedade resultante do uso de tecidos. Mechtild Flury-Lemberg, da Abegg-Stiftung Foundation de Berna, na Suíça, é uma das pesquisadoras mais respeitadas na área da conservação de têxteis e diz que "desde tempos imemoriais, os tecidos têm sido usados como artigos cotidianos para a proteção dos seres humanos do calor e do frio" (FLURY-LEMBERG, 1988, p. 13). É justamente por esta relação tão antiga com o corpo do ser humano que o traje (ou indumentária, vestimenta, costume...) recebe uma atenção tão particular nesta linha de pesquisa, que já categorizou os trajes.

A divisão foi estabelecida em três grandes categorias: eclesiásticos (o traje ritual ou ritualístico), militares (nas diferentes categorias) e civis (relativos ao cidadão em geral). 
O traje civil tem várias subdivisões- social, regional, profissional, interior, de folguedos e o traje onde temos desenvolvido a maior parte da nossa pesquisa com têxteis: o traje de cena, usado na realização de espetáculos teatrais, filmes, novelas e outras variantes cênicas.

Neste caso, o estudo histórico do teatro brasileiro e de tantas outras manifestações artísticas, poderia ser mais bem retraçado, se tivéssemos acesso minimamente aos vestígios materiais destas práticas. Uma das razões para que isso não ocorra é a desaparição e/ou destruição de objetos materiais que constituíram as peças e os teatros, desde o mais remoto início destas práticas no Brasil, que remontam a 1554.

A elaboração deste trabalho parte das evidências de descaso e/ou descuido observados em conjuntos de indumentária de diferentes coleções de têxteis brasileiros, que são trazidos à tona por diferentes profissionais. Quando as políticas de conservação são implantadas, o trabalho necessário de restauro tem grandes dimensões, já que durante muitos anos, como pôde ser presenciado, o conjunto de peças esteve acumulado em locais e em condições inadequadas.

Pela crença na riqueza e na importância desta espécie patrimonial específica, serão fornecidos subsídios para a maior compreensão dos materiais e estruturas, auxiliando em sua guarda, conservação e catalogação. Com isso, pretende-se aprofundar o estudo dos têxteis para fins de pesquisas históricas no Brasil e contribuir para que eles, enquanto não estiverem nas mãos de especialistas, possam receber cuidados mínimos necessários para garantir sua sobrevivência durante um tempo maior.

\section{Razões/fundamentação para a conservação dos trajes e têxteis}

No caso específico dos trajes e têxteis teatrais, pode-se ressaltar sua extrema importância para a preservação da história da arte brasileira e do teatro em particular. Contribui também para a compreensão de nossa cultura visual, uma vez que a experiência estética no teatro é, em parte, garantida pelos trajes de cena e pelos têxteis que compõem o próprio espaço arquitetônico, no cenário e na sala de espetáculos. Muito deste patrimônio já foi perdido, uma vez que relatos orais ou 
escritos, bem como ilustrações ou fotos, contam uma história que não pode ser tocada dada a inexistência de fontes primárias: neste caso, os trajes e têxteis.

De forma geral, há poucos tecidos ou trajes do período colonial, como aponta Teresa Cristina Toledo de Paula. Essa pesquisadora do Museu Paulista da Universidade de São Paulo acredita que muito pouca atenção foi dispensada a este tipo de material, o que teria gerado a tese de que o Brasil seria "um país sem tecidos, (...) o Brasil inventou-se sobre a ideia de ser uma cultura sem tecidos" (PAULA, 2006, p. 77).

No que se refere aos têxteis em geral e particularmente ao gênero teatral, o material referente ao século 19 não é tão escasso. Do século 20 há grandes coleções, como a do Theatro Municipal de São Paulo, com mais de vinte mil itens. Esta coleção, de valor fundamental para a história dos trajes cênicos na cidade de São Paulo, foi estudada no projeto Traje e Cena, com o apoio da Fundação VITAE, em 2005. O projeto foi coordenado por Fausto Viana e por Elizabeth Azevedo, do Departamento de Artes Cênicas da Escola de Comunicações e Artes da USP. Uma primeira publicação foi feita ao término do projeto em 2006: o Breve Manual de Conservação de Trajes Teatrais. (disponível para download em http://tramasdocafecomleite.files.wordpress.com/2009/08/manual-de-trajes.pdf)

Cada coleção precisa ser pensada de forma individualizada. Justamente daí surgem registros da importância da preservação e da análise documental deste tipo de patrimônio.

No exemplo dos trajes teatrais, sua utilização no espaço cenográfico dá lugar a combinações inusitadas em termos de materiais e de sistemas construtivos. Por não terem como premissa a durabilidade convencional das peças de uso diário, por vezes podem ser "auto-degenerativos", recorrendo a colas, tingimentos, metais e outros "beneficiamentos" que se danificam uns aos outros. Além disso, devemos considerar que a criação de figurinos de teatro, por caracterizar-se mais como uma atividade artesanal do que industrial (do ponto de vista do processo produtivo), não é facilmente reconstituída, sendo mais autoral do que social. Cada figurinista pode encontrar soluções únicas sem que elas se encaixem em um sistema industrial já 
conhecido como o das roupas sociais em geral, cujo conhecimento dado a priori auxilia nos processos de interpretação para futura conservação.

Cada categoria de traje deve ser pensada de forma particularizada, processo que muitos consideram uma tarefa árdua. O desafio inicia-se como bem lembrou Teresa Cristina Toledo de Paula ao citar Jennifer Harris:

\footnotetext{
Estudar tecidos depende, antes de tudo, da sobrevivência por séculos daqueles materiais naturalmente propensos à deteriorização e criados para serem usados e descartados. Estudá-los significa estudar o excepcional e o especial, já que o comum, de uso cotidiano, raramente sobreviveu a seu usuário. (PAULA, 2006, p.77).
}

Os têxteis empregados em teatro são diversos. No palco, poderiam ser nominadas as cortinas, as bambolinas (usadas para esconder do olhar do público as estruturas na parte superior do palco), as pernas (que são as estruturas que delimitam a saída de cena e a entrada nas coxias) e, entre outros, os telões pintados, que são feitos de papel (mas que têm em suas junções tiras de tecido para facilitar a dobra e o armazenamento). No setor da plateia, os assentos das cadeiras do público e todas as cortinas e acabamentos em material têxtil. A combinação "têxteis + papel" é muitas vezes complementada com a entrada da madeira nos cenários.

Isto é o que mais interessa do ponto de vista do estudo dos têxteis teatrais: são documentos, registros históricos de um período, um povo ou comunidade, uma forma de fazer. São materiais para estudos etno e antropológicos, marcos decisivos para o entendimento da condição humana. Não apenas para o entendimento do que já se foi, do que já passou. Não se trata também de alimento fetichista para os que encontram no passado uma suposta garantia de sobrevivência. São documentos que estavam inseridos em um contexto histórico e social, portadores de informações sobre seus usuários, produtores e até mesmo - no caso específico dos teatrais seus espectadores.

O traje pode indicar como foi manufaturado. Os materiais com que foi feito. Como foi feita sua modelagem, o que possibilita às vezes até que se identifique o seu 
fabricante. Pode indicar também sua origem, os caminhos que trilhou até chegar ao palco... São inúmeras possibilidades de pesquisa.

Rita Andrade afirma que estudar objetos, como as roupas e os tecidos de que são feitos, exige de nós habilidades que diferem do modo de análise de outros documentos, como os textuais e iconográficos. Analisar um vestido não é o mesmo que analisar a sua fotografia, assim como não seria o mesmo que analisar a sua descrição. O vestido, enquanto objeto material, enquanto coisa, tem uma série de características que the são próprias e cuja articulação constitui um artefato singular. (ANDRADE, 2006, p.72)

A inexistência de um traje deixa uma lacuna, que nem sempre é intransponível se houver minimamente uma imagem ou descrição dele. Mas a perda do objeto direciona o pesquisador para caminhos nem sempre fáceis de serem trilhados, posto que apoiados na dúvida e que dão margem a muitos questionamentos, principalmente de caráter científico.

É por isso que Andrade (2006, p. $74-75$, resumido) sugere que para a "leitura" de uma roupa não há como encurtar caminhos: é necessário passar por um procedimento metodológico de pesquisa, que abrangeria, em sua opinião, minimamente cinco questões:

1) Observação das características físicas, na busca de evidências internas do objeto através da percepção sensorial.

2) Descrição ou registro daquilo que está sendo estudado através de desenhos, descrição verbal ou escrita, gráficos, fotografias, maquetes, plantas baixas e mapas. 3) Identificação, que implica no reconhecimento, associando material aprendido anteriormente com o que é percebido no objeto.

4) Exploração ou especulação do problema, que é a fase do levantamento de hipóteses, discussão e questionamentos que surgem a partir das etapas anteriores.

5) Pesquisa em outras fontes e programa de pesquisa, que é o desenvolvimento de um programa de estudos que parte da análise de um objeto e se expande pela formulação de hipóteses.

\section{Conservação e conceitos aplicáveis aos trajes e têxteis}


Há algumas gerações despertamos para a necessidade da preservação com o principal intuito de possibilitar que gerações futuras usufruam dos mesmos recursos naturais que possuímos, assim como se aproximem de manifestações da cultura material ou imaterial que produzimos ou, ainda, que está preservada até então. Nessa meta, inserem-se amplos debates conceituais sobre a questão do restauro, da conservação, dos arquivos, dos dados e catalogação, da mudança de suportes, da recuperação de condições anteriores, enfim, uma série de variáveis que, de forma geral, são específicas da espécie patrimonial em questão.

O patrimônio da humanidade é muito diverso e inserido nele estão os têxteis. A preocupação com sua preservação como documentação é recente. Na Europa, as coleções de têxteis foram iniciadas em geral por membros da Igreja Católica ou das Casas Imperiais há bastante tempo. No entanto, um programa de conservação das mesmas só foi sistematizado a partir do final dos anos 1960 - no caso da Fundação Abegg-Stiftung, na Suíça e do Textile Museum em Washington, ou em 1975, na Inglaterra, no Victoria and Albert Museum.

No Brasil, de acordo com Teresa de Paula (1998, p. 72), na década de 1980 foram iniciados esforços introdutórios no CETIQT (Centro de Tecnologia da Indústria Química e Têxtil) no Rio de Janeiro, e depois atividades no Museu Histórico Nacional e no Museu da República. Na Universidade de São Paulo, a própria Teresa Cristina Toledo de Paula fundaria o Setor de Conservação de Têxteis do Museu Paulista da USP, em 1997.

No biênio 2008-2009, pudemos executar pesquisa prática nos seguintes museus europeus: Victoria and Albert Museum, em Londres e Museu da Moda, em Bath (Inglaterra); Centre National du Costume de Scène, em Moulins e Musée de la Mode e de Costume - Palais Galliera em Paris (França); Museo del Traje em Madrid e Museu de Terrassa em Barcelona (Espanha); Museu do Traje e Museu do Teatro, em Lisboa e Museu do Traje em São Brás de Alportel, em Viana do Castelo (Portugal). Há pelo menos três conceitos em suas áreas de atuação que são comuns: a conservação preventiva, a intervenção mínima e a reversibilidade. 
Conservação preventiva é um conceito quase autoexplicativo, que tem importância máxima nas coleções muito grandes de têxteis (no caso da Europa, são hoje cerca de cem coleções). Prevenir é melhor do que remediar: tratar sua coleção antes que os problemas possam surgir, como será visto a seguir. Cuidar do armazenamento, da limpeza, da manutenção, da quantidade de iluminação e de umidade relativa do ar... É muito mais viável economicamente prevenir do que tratar ou restaurar.

Intervenção mínima diz respeito ao padrão de restauro que deve ser aplicado em cada peça. Há quem defenda - e neste caso não há certo ou errado, mas sim opções - que a peça deve ser restaurada o máximo possível. Assim, substituições, reparos e outras intervenções poderiam ser aplicadas para que o objeto retornasse ao seu estado inicial.

$\mathrm{Na}$ verdade, este "retorno ao estado inicial" é utópico. A "história" da peça, as impressões nela das marcas do tempo seriam removidas, fazendo com que ela perdesse importância no ponto de vista da pesquisa investigativa. A intervenção mínima entra para garantir a sobrevida da peça, em condições saudáveis de musealização, sem alterar o que passou a fazer parte da sua constituição.

Reversibilidade é um princípio que garante que tudo que foi feito na peça possa ser desfeito diante do surgimento de novas tecnologias que permitam uma melhor proteção do objeto em questão. Tudo que altera o objeto de forma permanente, depois de ele ter se tornado objeto museológico, deveria ser evitado. Isso leva tanto o conservador como o restaurador a pensarem em suas linhas de atuação.

Cada objeto - tecido, roupa, estofado, cortina, o que quer que seja - deve ser encarado de maneira individual. Não existem fórmulas de atuação que sirvam para todos. As três regras acima são linhas de conduta e não fórmulas de execução, aplicáveis a todo tipo de trajes e não só aos têxteis teatrais.

Toda a linha de pensamento deste artigo é direcionada aos têxteis, como se vê. Mas, afinal, o que são "têxteis"? 
A definição mais básica acerca do que é um têxtil, é que se trata de um material fabricado por algum tipo de processo de tecimento. Esta definição é derivada do latim, raiz da palavra 'têxtil', textere, que significa tecer. O termo têxtil também pode ser aplicado a materiais manufaturados pelo entrelaçamento de fios, tais como objetos feitos pelo trançado, malharia e renda, bem como materiais não fiados, como feltros, nos quais as fibras ganharam coesão por tratamentos mecânicos ou processos químicos. Em casos raros, peles, couros e plásticos podem ser considerados têxteis, especialmente quando usados na manufatura de roupas. (LEENE, 1972, apud BITTNER, 2004).

Dentre as propriedades materiais específicas que mais interferem na diminuição de sua resistência material no ambiente e no tempo, estão a sua porosidade, dureza, (alguma) solubilidade, condutividade e combustão. De maneira geral, isso significa que sua estrutura molecular reconhece mais velozmente o atrito, a água, o calor, a água e calor na forma de umidade e a luz à qual se submete. Responde ainda ao contato com outros materiais que Ihe transmitem, em alguma medida, as suas propriedades físicas ou o destroem ao causar determinadas espécies de reações químicas.

Deve-se considerar, também, que as estruturas têxteis produzidas a partir das matérias-primas são mais ou menos resistentes às mesmas interferências (sobretudo ao atrito) conforme suas características de tecimento. Estruturas mais densas costumam ser mais resistentes devido à sua combinação material, o que impede que agentes externos deteriorem a estrutura por completo. Essa afirmação, contudo, sempre deverá ser relativizada, pois é totalmente vinculada ao tipo de exposição à qual o material foi/está submetido.

Os materiais têxteis desenvolvidos no último século, como as fibras de poliamida (nylon), acrílico, elastano (lycra) e poliéster, entre outras, reagem ao ambiente de maneira mais lenta, devido à sua natureza polimérica, podendo ser considerados genericamente plásticos. Isso não quer dizer que não se deteriorem nem que possam indistintamente ser submetidas a condições adversas. Porém, em suas características estritamente materiais (o que não vale para seu acabamento ou estrutura), têm maior chance de sobrevivência se não submetidos a agentes de destruição específicos e voluntários como o fogo ou químicos dissolventes. 
O material, devido à sua natureza, pode conduzir parte importante da reflexão sobre a sua preservação. A estrutura do tecimento, bem como o tipo de peça que foi confeccionada com determinado tecido, serão em maior ou em menor medida sujeitos à destruição. A depender da posição de um determinado tecido numa peça, o tipo de acondicionamento que foi feito e por quanto tempo se amoldou a essa posição, o tecido ou a construção (costura), podem destruir-se, sem que necessariamente as fibras sejam extintas. Por vezes, no entanto, é a destruição da fibra que causa danos à peça ou ao tecido, uma vez que desintegrada a estrutura, a peça perde parte de sua resistência ao seu próprio peso tanto em inércia quanto em movimento. Quando falamos de trajes de teatro, tanto durante a encenação quanto à posterior guarda devido ao fim de turnês, as peças recebem tratamento pouco cuidadoso, o que interferirá decisivamente em sua preservação.

Quando uma peça se transforma em acervo, talvez já tenha um nível de deterioração considerável. Por isso é necessário ao conservador de têxteis ou aos envolvidos no trabalho com acervos dessa natureza, o conhecimento a respeito dos princípios materiais elementares.

\section{Principais mecanismos e agentes de deterioração dos têxteis}

A deterioração dos têxteis é inevitável. No entanto, pode ser bastante retardada se forem dispensados os cuidados necessários a cada material, tanto do ponto de vista de sua matéria prima, quanto de sua estrutura plana e tridimensional (o tecido e a peça, considerados separadamente).

Não havendo necessidade de aprofundar as variáveis desse processo ao nível dos detalhes, cabe destacar, apenas, que a deterioração é tanto maior quanto a presença de substâncias agressoras das fibras, que podem ter sido incorporadas durante o processo de fabricação dos têxteis, quando de seu uso (sujeitos às bactérias/fungos do suor, por exemplo) ou de sua guarda e exposição (luminosidade, umidade etc.). Assim, por mais que uma peça têxtil tenha sido cuidadosamente tratada, a sua própria configuração, principalmente quando se trata de materiais de origem orgânica, dará início a um processo de 'autoeliminação'. 
Bittner (2004) enumera e localiza a origem dos tipos de agressões às quais os têxteis continuamente se submetem. São elas: os processos de acabamento que o configuraram, principalmente quando se trata da obtenção de determinadas cores ou de transformação de algumas propriedades dos materiais; a luminosidade, por ativar determinadas reações químicas degenerativas nos materiais e nos corantes e pigmentos que promovem o aspecto da coloração; a umidade, dado que as fibras com capacidade de absorção de água são distorcidas e deformadas e, ainda, cria-se um ambiente propício para a procriação de fungos, insetos e mofos que atacam as matérias, enquanto que a baixa umidade também contrai a fibra e diminui sua resistência; o calor, que provoca degradação da fibra de diferentes tipos segundo a sua origem (quebra, carbonização, derretimento etc.); e ação dos ácidos e álcalis, encontrados no ambiente, no contato com a pele humana ou em produtos que tangentes aos têxteis, causando a hidrólise, isto é, a dissolução parcial ou completa do material. Acrescentamos, ainda, o atrito e a força da gravidade, cuja ação é mais notada nas peças que não resistem ao seu próprio peso ou ao contato com outros materiais. 


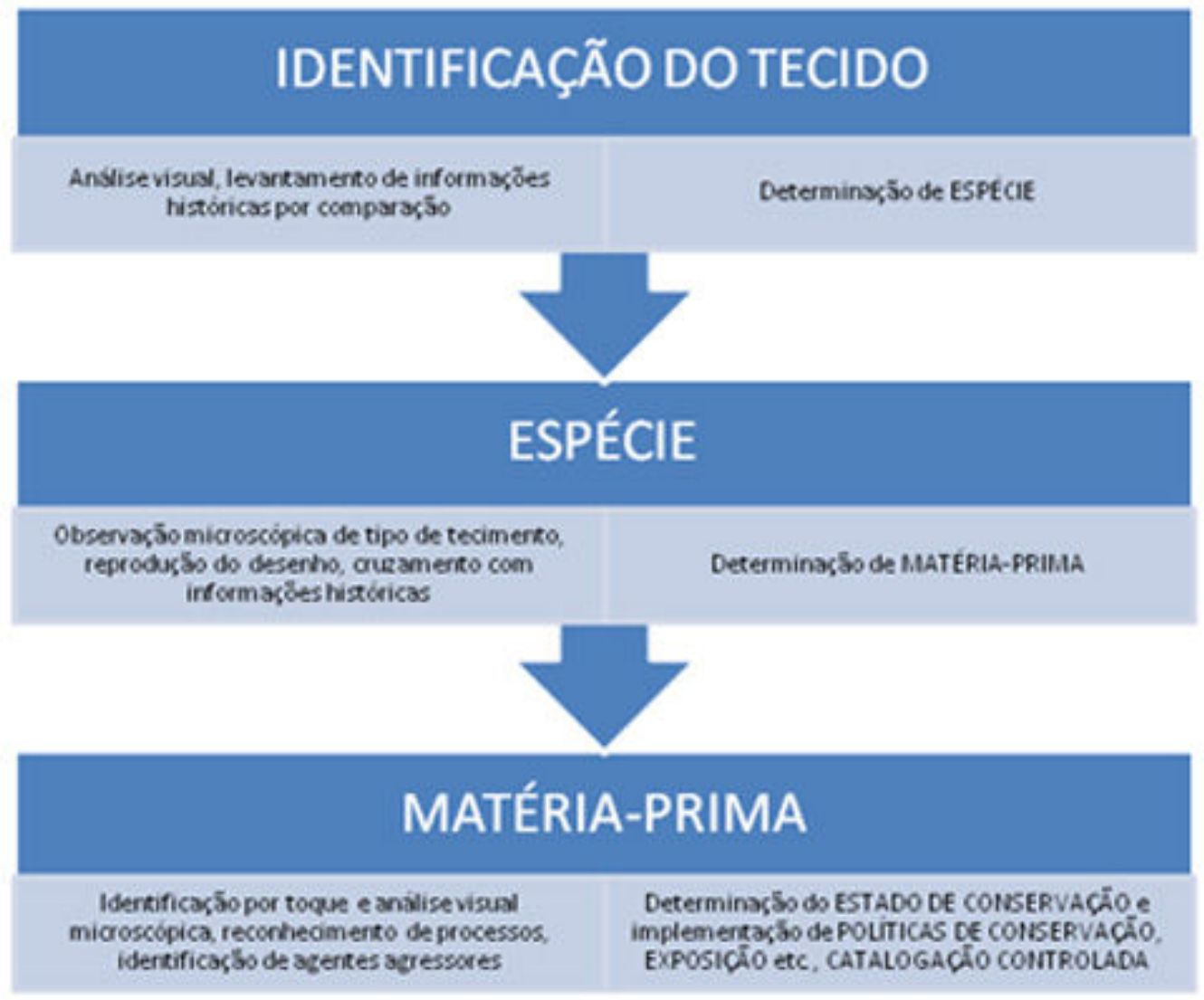

Figura 1-Proposta de organização (esquemática) da informação sobre os materiais téxteis, com vistas a promover sua melhor conservação

\section{Conceitos elementares sobre materiais têxteis, das fibras aos tecidos}

\subsection{Fibras}

A matéria-prima clássica dos têxteis é a fibra. Em suas principais descrições, encontramos como característica fundamental a relação de comprimento até 100 vezes maior que o seu diâmetro e, ainda, flexibilidade e preferência pré-definida de direção em sua estrutura molecular. (BITTNER, 2004).

As referências mais comuns nomeiam como filamento a fibra têxtil muito longa, semelhante a um fio de cabelo e, apenas fibra, àquela que vai de meia a algumas polegadas de comprimento (duas ou três). Pode ser considerada longa ou curta conforme sua extensão, a depender da categoria. Uma mesma categoria de fibra (por exemplo, a do algodão), pode ser longa ou curta conforme sua espécie botânica, o tipo de solo em que foi cultivado, etc. 
A principal classificação das fibras é conforme sua origem/obtenção. Podem ser naturais, subdivididas em animais (lã ou seda), vegetais (algodão, linho, rami, por exemplo) ou minerais (asbesto); ou químicas, podendo ser artificiais (obtidas pela regeneração de materiais naturais, como o rayon) ou sintéticas (obtidas a partir de polímeros, como a poliamida ou poliéster). Deve-se ainda considerar a existência de fibras metálicas. O contínuo desenvolvimento desse setor certamente ainda desenvolverá novas fibras.

\subsection{Fios}

Os fios são os materiais têxteis utilizados para o tecimento. Podem ser produzidos a partir de um único tipo de fibra ou pela mistura de diferentes fibras. O processo de obtenção dos fios chama-se fiação e, normalmente, essa etapa de processamento da matéria-prima têxtil concede ao fio características importantes para o aspecto final do tecido, além de determinar sua resistência à tração. Como os fios ainda podem ser misturados durante o tecimento, obviamente quaisquer de suas características não podem ser consideradas um fator único e decisivo na qualidade do produto final, mas são importantes variáveis a serem consideradas.

\subsection{Tecimento}

Os tecidos para as vestes, de maneira geral são obtidos por duas formas de tecimento: entrelaçamento de dois fios a $90^{\circ}$, chamados trama (horizontal) e urdume (vertical), ou pelo entrelaçamento de um mesmo fio entre si a partir da elaboração de laços de união. Existem também os não-tecidos, grupo dos quais fazem parte alguns têxteis técnicos e materiais menos nobres, como o feltro e o TNT. Esses não-tecidos são obtidos por diferentes técnicas de aglomeração de fibras não ordenadas.

Os primeiros são chamados tecidos planos ou de cala, nome dado à abertura dos fios de urdume para a passagem do fio de trama. Os segundos são os tecidos de malha, cujo mecanismo de obtenção é feito por sistema de uma ou mais agulhas em seqüência de tecimento tanto horizontal quanto vertical. Neste último caso, apesar de haver laços de união entre os fios caracterizando a malha, são necessários muitos fios de urdume (verticais) para o tecimento. 
O tipo de tecimento determina grande parte da estrutura têxtil, principalmente sua resistência à tensão, ao atrito e à gravidade. Os tecidos planos possuem uma maior estabilidade dimensional e, portanto, deformam-se menos. Os tecidos de malha, dada a sua 'amarração' por sistema de laços não atados, cedem às forças externas e possuem mais 'memória', isto é, retornam a um estado original com maior facilidade. É por essa razão que meias, lingeries, roupas esportivas etc., são produzidas com esse tipo de tecimento.

\subsection{Acabamento}

Chama-se acabamento ou beneficiamento ao processo final de melhoria da aparência e funcionalidade dos tecidos, tantos planos, quanto de malha. Existem processos que não trazem modificação à aparência final, como por exemplo, a rama, que trata apenas de estabilizar a dimensão do tecido, para que após as lavagens, ele não seja distorcido. Outros processos transformam aspectos estéticos e táteis dos têxteis, como a estampagem e o tingimento, que alteram cores e criam ornamentações, além de outros que conferem brilho adicional (mercerização) e criam aspectos avelulados (devorès, por exemplo), entre outros. Esses beneficiamentos tanto podem ser tratamentos físicos quanto químicos - podem, ainda, combinar ambos.

Os beneficiamentos muitas vezes causam desgastes às fibras e, por isso, são pensados de acordo com a natureza de cada matéria. Uma vez que praticamente todos os tecidos com os quais temos contato sofreram alguma espécie de beneficiamento, estes devem ser conhecidos para que possamos analisar sua influência sobre a deterioração da matéria têxtil. 


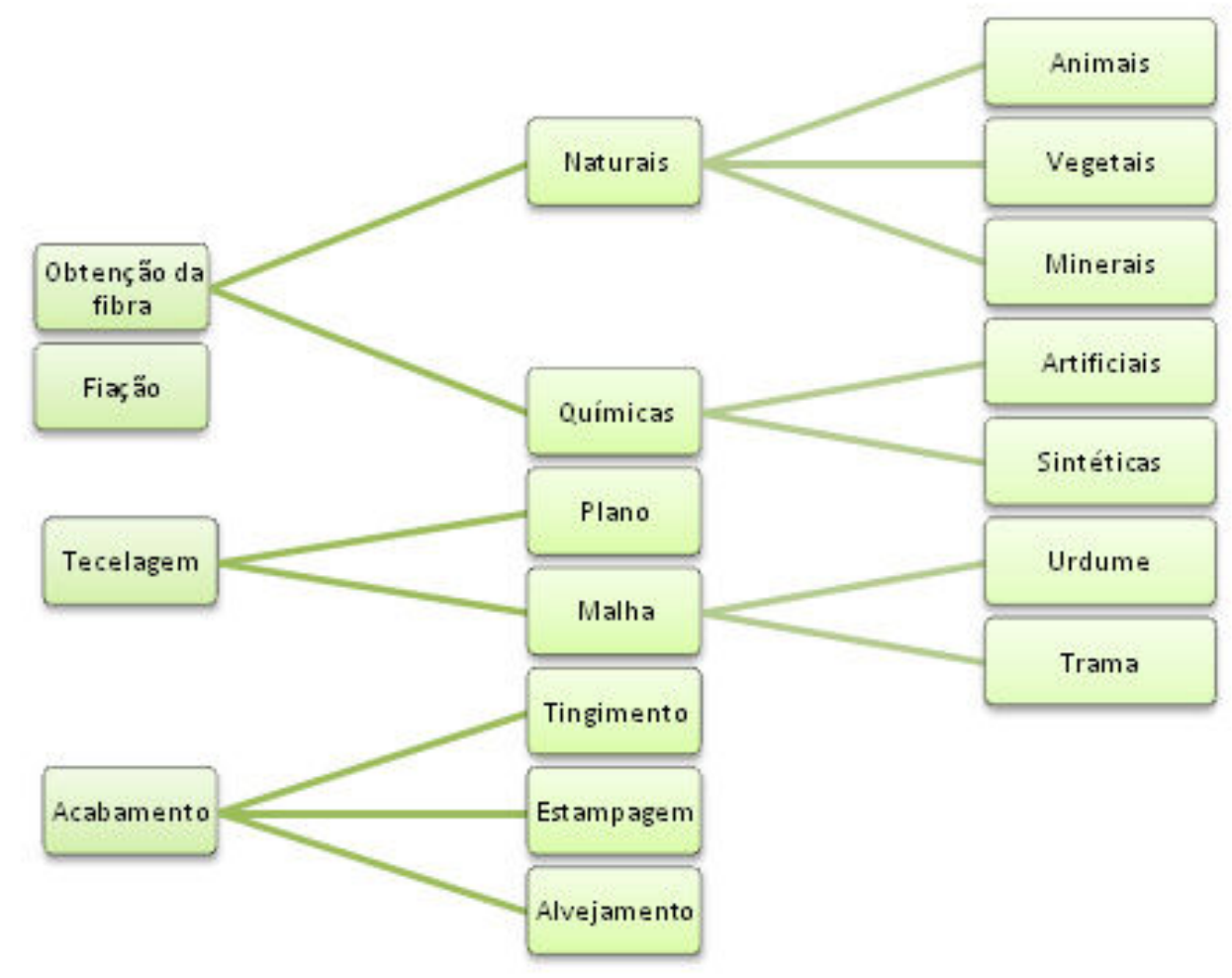

Figura 02- Fluxograma de produção têxtil resumido

\section{Reconhecimento dos têxteis, das fibras aos tecidos}

O tipo de material têxtil, a espécie de fio, a estrutura de tecimento, bem como a construção das peças acabadas, são as variáveis que devem ser consideradas frente à necessidade de se empreender práticas de preservação e guarda dos têxteis. Sabe-se, obviamente, que estas práticas são submetidas às políticas de preservação, que se encontram num campo filosófico que determina os princípios que regem a intervenção humana sobre os materiais considerados patrimônio.

Buscando apenas elencar as principais maneiras de reconhecer fibras e estruturas para poder determinar cuidados elementares necessários para que os têxteis mantenham por um tempo maior as condições nas quais se encontram em dado momento, apresentamos a seguir algumas etapas de apreensão dos materiais. Obviamente, não se tem a intenção de resgatar uma condição anterior ou de recuperar qualquer objeto têxtil, mas apenas manter a situação atual, isto é, aquela manifesta no primeiro contato com o objeto. 
Sue Kerry (2007), elaborou uma sequência didática a partir do acervo e da experiência do Victoria and Albert Museum em Londres que é útil neste momento. A partir de suas considerações, somando-as aos princípios anteriormente tratados, pode-se elaborar procedimentos simples e corretos para o tratamento dos têxteis.

\subsection{Reconhecimento da fibra e do fio}

A determinação da fibra poderá auxiliar na recuperação importante de dados sobre a peça (datação, origem geográfica etc.), bem como sobre que tipo de ação externa contribuiu para determinado estado de conservação e, principalmente, quais são as possibilidades de recuperação de propriedades originais. Deve-se tomar como base as referências sobre cada tipo de fibra e prestar atenção a referências históricas que contribuam para a localização dos têxteis no tempo-espaço.

Manuais de tecnologia têxtil descrevem as características da aparência das fibras, do seu toque e de reações a algumas intervenções, como a água ou ao calor, por exemplo. No caso dos têxteis de acervos, não é possível a execução de nenhum ensaio de reconhecimento destrutivo e, por isso, as fibras devem ser reconhecidas pela visão e pelo tato.

Os fios também podem ser identificados, verificando se o filamento é contínuo (como a seda ou algumas fibras artificiais) ou de fibras torcidas. Este tipo de observação é muito útil para interpretar técnicas de produção ou localizar os têxteis em um tempo histórico determinado. No entanto, também permite detectar possíveis fatores de degradação relacionados ao tipo de cada matéria prima. Pode ser útil, também, para a implantação de procedimentos de restauro complexo ou definir níveis de limpeza (aspiração ou lavagem, por exemplo). 


\begin{tabular}{|c|c|c|c|}
\hline Fibra & $\begin{array}{l}\text { Características } \\
\text { visuais }\end{array}$ & $\begin{array}{l}\text { Características } \\
\text { táteis }\end{array}$ & Outros \\
\hline ALGODÃO & $\begin{array}{l}\text { Em sua cor natural } \\
\text { é cru, as fibras } \\
\text { podem ter tamanho } \\
\text { variável. }\end{array}$ & $\begin{array}{l}\text { Toque suave, no } \\
\text { tecimento alguma } \\
\text { penugem resultante } \\
\text { do comprimento da fibra. }\end{array}$ & $\begin{array}{l}\text { Na queima } \\
\text { carboniza. }\end{array}$ \\
\hline $\mathrm{LA}$ & $\begin{array}{l}\text { Naturalmente } \\
\text { encrespada, antes da } \\
\text { lavagem é cru e às } \\
\text { vezes suja. }\end{array}$ & $\begin{array}{l}\text { Depende do tipo de origem, } \\
\text { mas o toque não é tão } \\
\text { suave e as formas originais } \\
\text { possuem mais memória, } \\
\text { estrutura volumosa. }\end{array}$ & \\
\hline SEDA & $\begin{array}{l}\text { De aparência } \\
\text { naturalmente } \\
\text { brilhante. }\end{array}$ & $\begin{array}{l}\text { Toque 'seco', } \\
\text { suave e agradável. }\end{array}$ & \\
\hline LINHO & $\begin{array}{l}\text { Fibras irregulares, no } \\
\text { tecimento se parecem } \\
\text { com uma tela. }\end{array}$ & $\begin{array}{l}\text { De toque mais áspero e } \\
\text { rígido que as anteriores, } \\
\text { não chega a ser } \\
\text { desagradável. }\end{array}$ & \\
\hline $\begin{array}{l}\text { POLIAMIDA } \\
\text { (Nylon) }\end{array}$ & $\begin{array}{l}\text { Aparência constante, } \\
\text { pode variar conforme a } \\
\text { espécie de extrusão. } \\
\text { Pode ser brilhante } \\
\text { ou opaca. }\end{array}$ & Tato suave e sedoso. & $\begin{array}{l}\text { Alta } \\
\text { resistência e } \\
\text { baixo peso. }\end{array}$ \\
\hline POLIÉSTER & $\begin{array}{l}\text { Podem 'imitar' diferentes } \\
\text { fibras, de acordo com a } \\
\text { espécie de filamentos. }\end{array}$ & $\begin{array}{l}\text { Depende do tipo de } \\
\text { fiação e extrusão, } \\
\text { pode ser contínua } \\
\text { (toque liso) ou } \\
\text { encrespada } \\
\text { (toque áspero). }\end{array}$ & $\begin{array}{l}\text { Alta } \\
\text { durabilidade } \\
\text { e } \\
\text { resistência. }\end{array}$ \\
\hline $\begin{array}{l}\text { SPANDEX } \\
\text { (lycra) }\end{array}$ & $\begin{array}{l}\text { Sempre se utiliza } \\
\text { misturado em outras } \\
\text { fibras. }\end{array}$ & $\begin{array}{l}\text { Confere característica } \\
\text { de elasticidade ao } \\
\text { tecido. }\end{array}$ & $\begin{array}{l}\text { Rompe ao } \\
\text { estirar-se } \\
\text { demasiado. }\end{array}$ \\
\hline
\end{tabular}

Tabela 01- Fibras e suas características

\subsection{Reconhecimento da estrutura de tecimento}

Como dito anteriormente, existem dois tipos básicos de construção de uma estrutura têxtil, sendo o tecido plano e o tecido de malha. Cada um desses tipos é obtido por diferentes técnicas e com o uso de equipamentos distintos, como teares manuais, verticais, horizontais, automatizados e outros. 
Além dos tipos de tecimento, conforme a estrutura elementar de obtenção dos tecidos (plano ou malha) seria possível identificar os diferentes tipos de teares ou instrumentos de produção utilizados no fabrico dos materiais, No entanto, dada a proposta deste artigo, este item não será abordado.

O tipo de tecimento é facilmente reconhecível pela utilização de uma 'lente conta-fio' ou um microscópio, que proporcionando a ampliação da trama, nos permite retraçar a padronagem do tecido.

Tipo

Tecido plano

Tecido de malha (à direita: trama e à esquerda: urdume)

\section{Diagrama elementar}
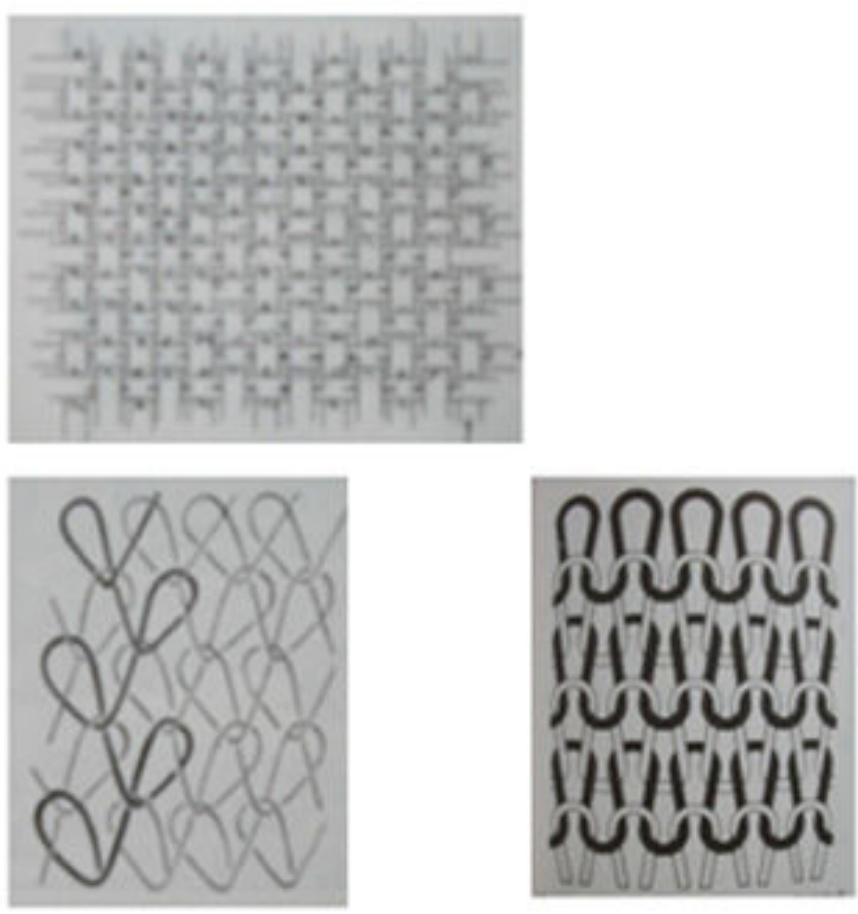

Tabela 02- Os tipos de tecimento

\subsection{Reconhecimento das etapas de beneficiamento}

É o conhecimento dos sistemas de produção e beneficiamentos de tecidos, que permite que façamos qualquer identificação dos recursos utilizados para a obtenção dos efeitos finais e de sua possível interferência sobre o desgaste ou sobre o cuidado necessário aos têxteis. Trata-se, praticamente, de decodificar a partir de um código que conhecemos previamente. 
A etapa de beneficiamento, de modo bem generalista, tem a missão de alterar alguma propriedade essencial da matéria (bruta ou na forma de substrato). Por exemplo, o alvejamento aplicado ao algodão trata de clarear a fibra, que naturalmente tem um tom cru. Só se pode saber se um tecido de algodão foi alvejado ao se reconhecer o processo e as principais características das fibras.

É importante o reconhecimento da presença, em sua origem, de alguns tipos de beneficiamento. Eles poderão, de certa forma, recuperar informações sobre os tecidos que o tempo apagou. Isso se refere a alterações de cores de tingimento e estampagem; brilhos ou escurecimentos decorrentes do contato com uma fonte de calor; desaparecimento de algumas fibras da composição do tecido pelo uso de alvejantes na lavagem ou até mesmo pelo suor, entre outros.

Não há, portanto, uma maneira de apresentar a priori todos os acabamentos/beneficiamentos possíveis sobre os têxteis. Os principais são alvejamento, tingimento e estampagem.

Alvejamento - ação que tem o objetivo de despigmentar fibras que, naturalmente, são amareladas. Também pode aparecer como efeito de design no desbotamento dos índigos (jeans), por exemplo. Funciona a partir da imersão do tecido, dos fios ou das fibras em banhos aquosos com Peróxido de hidrogênio $(\mathrm{H} 2 \mathrm{o} 2)$ ou Hipoclorito de Sódio ( $\mathrm{NaClO})$, conhecidos comercialmente como água oxigenada e cândida. São processos químicos que danam qualquer espécie de fibra, que vão tornando-se menos resistentes. Algumas fibras químicas podem ser totalmente destruídas por esses agentes. O alvejamento é facilmente identificado, já que concede às FIBRAS NATURAIS o chamado branco ótico em diferentes níveis. As fibras artificiais NÃO são alvejadas, pois naturalmente já podem ser brancas.

Tingimento - Com a utilização de corantes, isto é, substâncias químicas dissolvidas em água nas quais se mergulha o tecido, a fibra ou os fios, a matéria-prima crua ou alvejada pode receber cor sobre ela. Cada tipo de corante e banho é adequado para um tipo de material e, alguns deles, são danosos às fibras ou menos resistentes à ação da luz, que com o tempo podem despigmentar-se total ou parcialmente, transformando algumas cores. É importante que o conservador conheça essas 
possibilidades, uma vez que, muitas vezes, observa um tecido com a cor transformada pela ação do tempo.

Estampagem - Processo de elaboração de ornamentos sobre os tecidos, com a utilização de corante ou pigmentos. Enquanto os corantes 'penetram' nos fios e fibras, o pigmento é uma película que se sobrepõe à matéria, a partir de um recurso químico de construção de uma pasta viscosa aderente ao substrato. Normalmente, a estampagem acaba por determinar o avesso e o direito do tecido, uma vez que o pigmento, utilizado majoritariamente, concentra-se em um lado da peça. A ação da luz também pode despigmentar a cor, porém, no caso dos pigmentos, o atrito durante o uso também é razão comum para danar fisicamente a estampa, especialmente em têxteis mais antigos, quando as tecnologias de fixação não estavam tão desenvolvidas.

\section{Principais estruturas têxteis}

É praticamente impossível descrever e exemplificar todas as espécies especiais de estruturas têxteis, obtidas não só pela combinação de matérias-primas como por meio de teares específicos e acabamentos diferenciados. No entanto, existem alguns tecidos clássicos, que surgem reincidentemente nos acervos e que ainda fazem parte do comércio. Pode-se organizá-los a partir da idéia de que determinado tecimento ornamental, provoca um resultado distinto. 

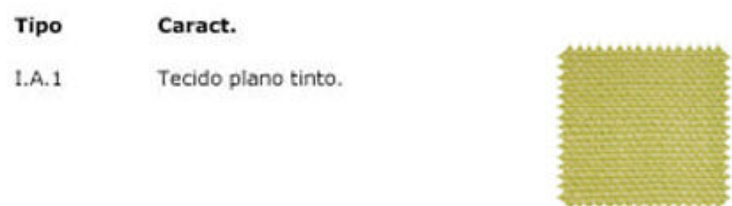

$\begin{array}{ll}\text { II.A.1 } & \text { Renda de nylon. } \\ \text { 1.A.2 } & \text { Tecido plano estampado. } \\ \text { II.B.1 } & \text { Malharia retilinea, com fio de } \\ \text { acrilico ou lã. } & \\ \text { 1.A.3 } & \text { Tecido plano com fios tintos, no } \\ \text { entrelaçamento da trama/ } \\ \text { urdume formando riscados ou xadrez. }\end{array}$
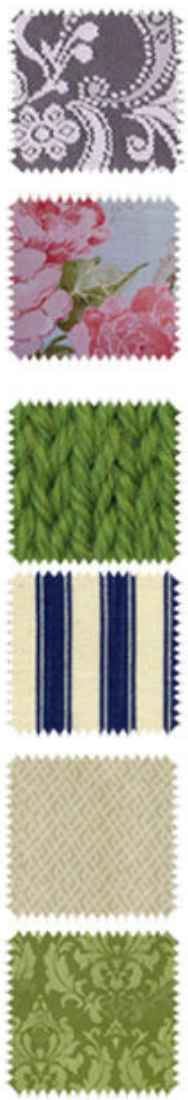

III.A

Rendado no fio, onde o tecido e construido simultaneamente ao efeito rendado (áreas vedadas e vazadas), como o crochê, o bilro e outras rendas.

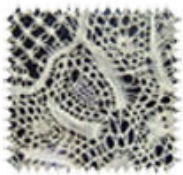

1.B.2 Brocados.

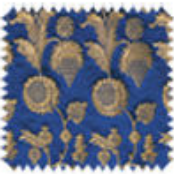

III.8 Rendado no tecido, onde a renda e do re-arranjo dos fios, como o labirinto, richelieu e outros.

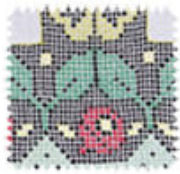

1.B.3 Piqué, tecido onde os fios de
urdume/trama entrelaçam-se formando pequenos desenhos.

II.A.2 Tecidos performáticos, com uso de nylon e lycra.

Tabela 03- Tecidos dássicos e algumas caracteristicas 


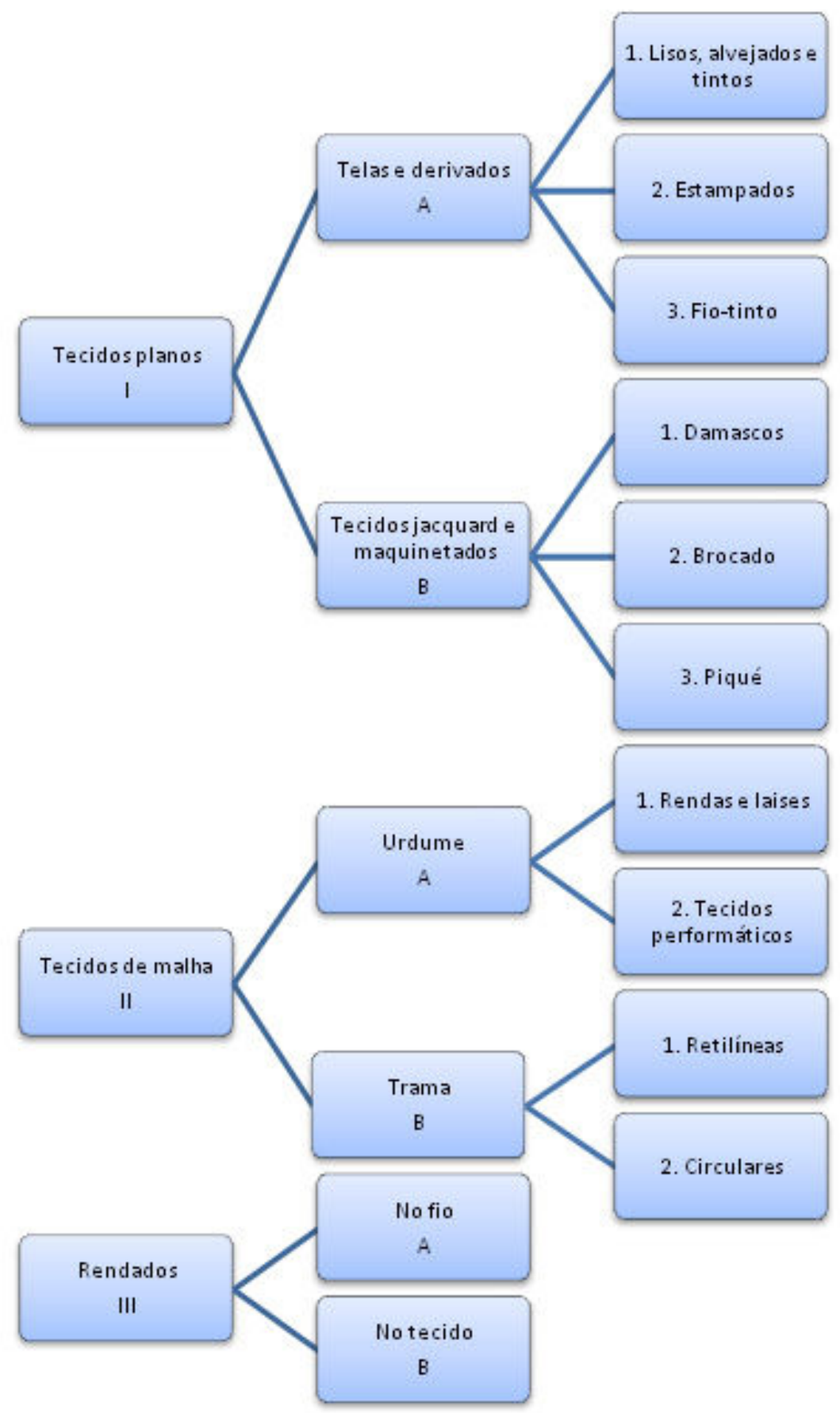

Figura 03 - Alguns tipos elementares de têxteis

\section{A conservação de têxteis - sugestões oficiais, práticas e muito úteis}

O Breve Manual de Conservação de Trajes Teatrais oferece a descrição completa de como foi realizado o trabalho no Theatro Municipal de São Paulo. Mostra toda a trajetória percorrida desde o início dos trabalhos de separação e higienização até a catalogação e armazenamento da coleção. 
No entanto, para complementar este artigo, julgou-se oportuno recuperar o documento do ICOM (Conselho Internacional de Museus) que firmou um roteiro de conservação de têxteis. A intenção foi trazer ao leitor que não é conservador profissional idéias sobre o que pode ser feito quando não há por perto um conservador ou restaurador profissional. Ou seja, como garantir a sobrevida, a salvaguarda da sua coleção sem que maiores danos possam destruí-la.

\subsection{Adquirindo informações}

Tentar identificar de onde a peça veio, como chegou àquele local. Nomear o dono anterior, de forma clara, em um caderno simples. Ver se há alguma foto que mostre o objeto sendo usado. Anotar se o objeto foi comprado, doado ou encontrado em algum lugar. Descrever os adereços que o complementam. Fazer uma breve descrição da peça, descrevendo suas cores, seu formato, seu tecido, seu peso. Se a peça tiver pedaços soltos, guardá-los com cuidado, em pequenos sacos plásticos para que não se percam, identificando o saquinho e guardando-o em um lugar reservado. Não deixar nada grudado no traje com alfinetes, clipes, pregadores ou grampos - o tecido pode ficar manchado. Fotografar o traje - pode ser uma ajuda essencial se acontecer alguma coisa com a peça.

Se o acervo for muito grande, as instruções de catalogação no Pequeno Manual poderão ser muito úteis. Lembrar que os têxteis carregam, normalmente, muitas sujidades. Não mexer neles sem uma luva, de algodão ou descartável. Não coçar o nariz ou os olhos para evitar irritações de pele e infecções. De preferência, usar máscara descartável e trabalhar em um ambiente com boa ventilação.

\subsection{Conservação}

Conservação é trabalho de profissionais, não há a menor dúvida. Para a pessoa que não tem formação profissional nesta área, o melhor é não interferir. Não fazer nada se não souber como proceder, e principalmente, não tomar nenhuma atitude que possa danificar a peça de forma permanente. Lembrar que este é o momento de aplicar os conceitos de reversibilidade e intervenção mínima. Por exemplo, não se pode lavar uma peça com alvejante do tipo cândida. Ela vai danificar o tecido de forma permanente, além de apagar impressões que poderiam fornecer excelentes 
estudos para um pesquisador. Na verdade, a lavagem deveria ser feita por um profissional de restauro, que saiba lidar com peças históricas.

Pode-se, por exemplo, substituir fitas de decoração, rendas e outros ornamentos por material mais novo, com cores mais vivas. Não deveria, pois isto impede que um conservador ou restaurador possam identificar as melhores opções para aquela peça. Lembrar que tudo que for feito deverá poder ser desfeito. Se trocar peças menores, como lacinhos, guardar os velhos e fazer fotos com câmera digital (que hoje são acessíveis e têm preços bons) de como eles estavam aplicados na peça. Mexer o mínimo possível na peça.

Ficar sempre atento à presença de parasitas (que agem química ou fisicamente nas matérias têxteis e por isso as degeneram) que possam destruir os têxteis. Separar da coleção se houver algum traje infestado e tratá-lo - ou ainda melhor, enviá-lo para que um profissional trate. De maneira alguma pendurar nos armários, baús ou qualquer local em que os têxteis vão ficar armazenados cascas de limão, de laranja, ou naftalina. Manter contato com uma empresa especializada e fazer dedetização.

Resistência à tentação. Não vestir e nem permitir que vistam os trajes antigos para festas, exposições, reuniões, para mostrar aos amigos, etc. O dano vai ser permanente, indício de que não vale o risco. Sugerir sempre o uso de réplicas feitas com base no material do acervo.

Mais uma vez, usar luvas de algodão ou descartáveis para lidar com a peça, para não sujar ainda mais o objeto. Deixar a limpeza para os profissionais, e isso quando der. Não lavar os têxteis antigos de qualquer forma - o dano vai ser permanente.

Não confiar em qualquer um que diz que sabe costurar as partes soltas e fazer restauro em têxteis. Analisar sempre se é um profissional qualificado e acima de tudo, usar bom senso. Não entregar bens valiosos nas mãos de pessoa qualquer. Fazer uma limpeza superficial, remover o excesso de pó com um pincel, por exemplo, e aguardar a ajuda profissional.

\subsection{Arrumação}


Evitar as grandes variações climáticas no local onde estão os têxteis. O ICOM recomenda as seguintes condições atmosféricas:

- Para os têxteis: $18^{\circ} \mathrm{C}$ (temperatura) e 50-55\% (Umidade)

- Para o couro: $18^{\circ} \mathrm{C}$ (temperatura) e $50 \%$ (Umidade)

Procurar deixar a peça sempre no escuro, para que ela não desbote com a luz artificial ou do sol. Iluminar só quando for trabalhar com o objeto.

Guardar, se for uma peça frágil, em uma caixa, na horizontal. Atenção: não usar papel de seda azul como mandavam fazer as gerações anteriores, para evitar transferência de cores. Se for uma peça resistente, de tecido forte, pendurar normalmente, deixando distância entre os trajes para que as cores não passem de um para outro e, pior, uma enganche na outra e o traje acabe fatalmente rasgado.

Usar para separar as peças TNT branco, por exemplo, que é bastante econômico e não vai permitir a transferência de cores.

O local em que as peças estão deve estar sempre limpo e arrumado. Não permitir que pessoas estranhas fiquem manuseando os objetos. Averiguar se não há no espaço reservado aos têxteis nenhum tipo de praga: cupim, traças, formigas, etc.. Mais uma vez, não colocar venenos ou inseticidas junto aos têxteis.

Pequenos cuidados aliados a bom senso são a fórmula do sucesso na conservação de têxteis.

\section{Conclusões}

Durante milhões de anos, vestuário e ornamentos foram usados de modo a que pudessem comunicar as suas maiores necessidades. As pessoas. A tradição. $O$ progresso. $O$ novo tribalismo. A autenticidade. No meio de tudo isso apenas um único fator permaneceu idêntico: a extraordinária capacidade semiótica do corpo humano, do vestuário e dos ornamentos. (TED POLHEMUS, apud BALDINI, 2005, p. 9).

É fundamental, em primeiro lugar, que se trabalhe com o potencial dos têxteis como patrimônio documental da humanidade. Impregnados de história e informações, 
servem como base de estudos para a etnologia, a antropologia e muitas outras como a arqueologia funerária (que procura entre outros desvendarem o traje vestido pelos despejos humanos encontrados) e a criminalística (que investiga vestígios de pólvora e sangue para obter dados do crime).

O estudo dos têxteis não se refere apenas a peças de museu - muito ao contrário, seu uso na contemporaneidade vem sendo expandido de forma exponencial. Considerando que a produção de têxteis ou a criação de objetos produzidos a partir de tecidos ampliam-se em possibilidades na medida em que as tecnologias de produção se desenvolvem, é impossível propor um trabalho que esgote todas as variáveis materiais. Do ponto de vista da recuperação histórica a mesma consideração é válida, pois, apesar de terem sido desvendadas muitas técnicas de produção de têxteis, muito ainda está por se descobrir ou por reconsiderar, pois esse campo ainda apresenta grandes lacunas.

No campo da conservação, pode-se dizer o mesmo. Apesar das regras terem sido estabelecidas há algum tempo e mudado muito pouco, novos recursos estão cada vez mais surgindo; novas possibilidades de conservação vão se abrir. É um momento histórico curioso, em que muitas tecnologias estão envolvidas tanto no desenvolvimento de novos produtos como na conservação deles.

O mais importante, dentro dessa proposta, é estabelecer um método de trabalho calculado para cada peça de uma coleção. Cada item terá que ser tratado de acordo com o seu material, sua composição, seu formato... É bastante raro poder tratar todos os itens de uma coleção de têxteis de uma mesma maneira.

Este artigo cerca as principais questões que podem incomodar iniciantes no assunto. Procurou-se atender à demanda de instrumentalizar tecnicamente, ainda que em nível inicial, as pessoas envolvidas com a conservação, preservação, guarda ou catalogação dos têxteis.

A partir do trabalho, da relação dos historiadores, curadores, estudantes e outros profissionais da área com os materiais têxteis, muitas pesquisas vêm sendo e serão desenvolvidas. Seu campo de aplicação será cada vez mais difundido. 
O estudo dos têxteis no formato vestuário fornece material de aplicabilidade imediata- da conservação aos grandes faturamentos da indústria da moda. No caso de tapeçarias históricas, por exemplo, que por si só já seriam suficientes para um artigo científico amplo e complexo, há um arsenal de informações que vão desde o material usado no tingimento dos fios até a identidade de quem pagou pela sua execução, no caso das tapeçarias comemorativas de um grande feito militar, por exemplo.

A conservação de têxteis é um campo recente e promissor no que se refere a estudos acadêmicos mais sistemáticos. Desponta como uma linha de pesquisa que tende a se desenvolver e atrair cada vez mais pessoas para seu campo de atuação.

\section{Referências bibliográficas}

ANCHIETA, José. Teatro de Anchieta. São Paulo: Edições Loyola, 1977.

ANDRADE, Rita. Por debaixo dos panos: cultura e materialidade de nossas roupas e tecidos. In: PAULA, Teresa Cristina Toledo de. Tecidos e sua conservação no Brasil: museus e coleções. São Paulo: Museu Paulista da USP, 2006. p. 72-76.

BALDINI, M. A invenção da moda. Lisboa: Edições 70, 2005.

BITTNER, E. Basic Textile care: structure, storage, and display. Apostila da Disciplina Introduction to the Structure and Technology of Records Materials. Texas: Universidade do Texas, 2004.

FLURY-LEMBERG, Mechthild. Textile conservation and research. Berna: Abegg-Stiftung, 1988.

HOLLEN, N.;SADDLER, J. Introducción a los textiles. México: Editorial Limusa, 1994.

KERRY, S. Identifying textile types and weaves, 1750-1950. London: DATS, 2007.

MAGALDI, Sábato. Panorama do teatro brasileiro. São Paulo: Global, 1999.

PAULA, Teresa Cristina Toledo de. Inventando moda e costurando história: pensando a conservação de têxteis no Museu Paulista/USP. Dissertação (Mestrado)-Escola de Comunicações e Artes, Universidade de São Paulo, São Paulo, 1998. 
2006.

SCHOESER, M. World textiles: a concise history. London: Thames \& Hudson, 2003.

SYKAS, P. Identifying printed textiles in Dress, 1740-1890. London: DATS, 2007.

\section{Créditos}

*Professor livre docente do Departamento de Artes Cênicas da Escola de Comunicações e Artes da Universidade de São Paulo (ECA-USP).

e-mail: faustoviana@uol.com.br

**Doutoranda do Departamento de História da Arquitetura da Faculdade de Arquitetura e Urbanismo da Universidade de São Paulo (FAU-USP) e docente do Centro Universitário Senac-SP.

e-mail: design.textil@uol.com.br 